\title{
Day-of-the-week effect in the Nigerian Stock Market Returns and Volatility: Does the Distributional Assumptions Influence Disappearance?
}

\author{
Osabuohien-Irabor Osarumwense*
}

\begin{abstract}
:
This study assesses the influence of error distributional assumption on appearance or disappearance of day-of-the-week effects in returns and volatility using the Nigerian stock exchange (NSE-30). The Gaussian, Student-t, and the Generalized error distribution were incorporated in the GARCH $(2,1)$ and EGARCH $(2,1)$ models. Result reveals that day-of-the-week effects are sensitive to error distribution. Our finding also shows that evidence of good or bad news in volatility does not only depend on the asymmetric model but also the choice of the error distribution. Thus, this study will provide adequate knowledge to policy makers, investors and researchers about day-of-the-week effect in stock markets.
\end{abstract}

Key words: Stock; GARCH; Disappearance; Day-of-the-week; Model.

JEL classification: $\mathrm{C} 22, \mathrm{G} 12, \mathrm{C} 12$.

\section{Introduction}

Day-of-the-week effect in the Nigeria stock exchange market has been widely studied and documented in finance literature. In develop market, studies by Cross (1973), French (1980), Gibbons and Hess (1981), Berment et al (2007), Basher and Sadorsky (2006), Brooks and Persand (2001), Charles (2010), Kein and Stambangh (1984) etc, demonstrated that there are differences in distribution of stock returns and volatility for each day-of-the-week. Researchers that have also investigated whether these anomalies exist in developing market, particularly the Nigerian stock exchange includes; Umar (2013), Chipili (2012), Osazevbaru and Oboreh (2014), Oladayo (2015), Alagidele (2008), Ajibola (2014) etc. Due to volatility behavior of the stock prices, majority of these researchers have investigated this daily anomaly using the non-linear model of either the generalized autoregressive conditional heteroskedasticity $(\mathrm{GARCH})$ or the exponential generalized autoregressive conditional heteroskedasticity (EGARCH) model.

Osabuohien-Irabor Osarumwense; Department of Mathematics \& Statistics, Ambrose Alli University (AAU), KM 70 Benin Auchi Road, P. M. B 14, Ekpoma, Nigeria; and Department of Statistics, School of Mathematical Sciences Universiti Sains Malaysia, 11800 Gelugor, Penang, Malaysia, <osabuohienosa@aauekpoma.edu.ng; osabuohien247@gmail.com>. 


\section{Osarumwense, O.: Day-of-the-week effect in the Nigerian Stock Market Returns and Volatility: Does the Distributional Assumptions Influence Disappearance?}

Fast growing numbers of researchers (Charles (2010), Saadi et. al (2006)) etc with empirical evidence have supported the argument that the day-of-the-week anomalies are nothing but a fiction, imagination and inadequate application of methodology. Saadi noted that evidence of the day-of-the-week effect is not robust to a GRACH model with normal, student-t, GED or the double exponential error distribution. Because Nigerian Stock Exchange serves as the second largest financial centre in sub-Saharan Africa, the third largest stock exchange in Africa by capitalization and the largest market in West Africa. With this, most researchers have investigated the day-of-the-week in mean and/or volatility under different distributional assumptions. But will these error distributions show consistencies or otherwise if mounted on the same model? To answer this question is the central objective of this study which is to investigate whether the appearance or disappearance of the day-of-the-week effects varies under different error distributional assumption. The remainder of this paper is organized as follows; Section 2 contains a brief review of history and development of the Nigeria stock exchange. Section 3 presents a review of literature on day-of-the-week effect. Section 4 deals with the preliminary analysis of data and methodology used in the study. Section 5 discuses the application of data to the various models as well as the empirical results of the application. Section 6 draws conclusion as well as appropriate recommendation.

\section{Literature review of related studies}

There are many literatures on the day-of-the-week effects in the Nigeria Stock Market. Some include; Ajobola and Nwakanma (2014), how investigated market anomalies using 140 listed companies in the Nigeria equity market. They employed both the parametric and non-parametric methodology. Using the normal error distribution assumption with GARCH and TGARCH model, they concluded that there is a significant market anomaly in the Nigeria stock exchange. Other non-parametric methods used are the Lilliefors, Crammer-Von-mises, and the Anderson-Darling tests.

Umar, (2013), investigated the day-of-the-week effects for the Nigerian and South African equity markets for over pre-liberalization and post-liberalization periods. The exponential generalized autoregressive conditional heteroskedasticity (EGARCH) model was used to estimate the day-of-the-week effect both in the mean and variance equations. Evidence of day-of-the-week effect was found in both the mean and variance equation for the Nigeria and South African equity markets. Osazevbaru and Oboreh (2014) also investigated the Nigerian stock market anomalies using the OLS methods and the GARCH model under the normal error distribution assumption with data spanning from January 1995 to December 2009. They found anomaly in the Nigerian stock market for Monday 
effects. Using one hundred and sixty-seven (167) stocks all share index listed on the Nigerian stock market (NSE-ASI) between the period of 2004 and 2014, the January and Monday effects found no significant evidence in January and day-ofthe-week effects. Olowe (2014) also investigated day-of-the-week effects in the Nigerian foreign exchange market using the GARCH and GJR-GARCH models under the normal error distributional assumption for period of January $2^{\text {nd }} 2002$ to March $13^{\text {th }} 2009$. Although the results failed to support the presence of the day-ofthe-week in the FOREX rate returns, but there was evidence of the effects in the volatility. The GARCH model was found to fit better than the GJR-GARCH model for the data used.

Other extensive studies that have investigated the day-of-the-week anomalies for different stock markets around the world include but not limited to; Al-Mutairi (2010) found evidence of presence of the day-of-the-week effect in Kuwait stock exchange. His findings show that Saturday returns were positive and higher than other days of the week except for Wednesday, suggesting that Kuwait stock market is inefficient. Rozeff \& Kinney (1976) in their study of the New York Stock Exchange found that seasonal patterns were present in the New York Stock Exchange Price Index. They found that average returns in January were seven times that of the average returns of the other eleven months. Gultekin \& Gultekin (1983), using both parametric and non-parametric methods, found statistical evidence of January effect in thirteen out of the seventeen stock markets of the industrialized countries studied. Kiymaz and Berument (2003), investigated the day-of-the-week effect on the volatility of major stock market indexes for the period of 1988 through 2002. They found that the day-of-the-week effect is present in both return and volatility equations. They found volatility occurs highest on Monday for Germany and Japan and on Friday for Canada and the United States, while on Thursday for the United Kingdom (UK). Claessens et. al, (1995) examined the seasonal effect for many emerging countries and found that only few countries showed evidence for January effect like Republic of Korea, Turkey, and Mexico. However, many countries had shown the abnormal return in other months besides January (e.g., April in Brazil, October in Argentina and Chile, December in Pakistan, etc.).

\section{Materials and methods}

\subsection{Preliminary analysis of data}

The historical daily price data of the Nigerian stock exchange for top thirty leading companies (NSE-30) from $31^{\text {st }}$ May 2011 to May $2^{\text {nd }} 2015$ was used. Table 1 shows that daily stock returns have daily weekly average positive return of about $15 \%$, and $3 \%$ for all days' data. There is high excess kurtosis and skewness indicating that the series is non-symmetric with higher peak and fatter tails than the normal distribution. Initial findings show that daily returns are not normally 
Osarumwense, O.: Day-of-the-week effect in the Nigerian Stock Market Returns and Volatility: Does the Distributional Assumptions Influence Disappearance?

distributed. They are leptokurtic and skewed. The return in each day $\left(R_{t}\right)$ are expressed and calculated as the first logarithmic difference of the series in percentage, given as;

$$
R_{t}=100 X \log \left[\text { Stock } P_{t} / \text { Stock } P_{t-1}\right]
$$

Where $P_{t}$ and $P_{t-1}$ are prices of stock for current and previous days respectively.

\section{Tab. 1: Summary Statistics for NSE-30 Returns}

\begin{tabular}{lllllll}
\hline Observations & Monday & Tuesday & Wednesday & Thursday & Friday & All Days \\
\hline Panel A: & & & & & & \\
Sample Mean & 0.1569 & 0.1455 & 0.1473 & 0.1504 & 0.1530 & 0.0305 \\
Std.Derivation & 2.8436 & 2.7879 & 3.0298 & 3.1957 & 3.0474 & 0.9997 \\
Skewness & -0.3324 & -0.3241 & 0.6729 & 0.6640 & -0.2240 & 0.3049 \\
Kurtosis & 4.5779 & 2.8774 & 8.9740 & 8.4962 & 5.5073 & 7.7739 \\
(excess) & & & & & & \\
Jarque-Bera & 181.8982 & 73.9497 & 699.9414 & 628.5729 & 259.5237 & 2594.3739 \\
& {$[0.0000]^{*}$} & {$[0.0000]^{*}$} & {$[0.0000]^{*}$} & {$[0.0000]^{*}$} & {$[0.0000]^{*}$} & {$[0.0000]^{*}$} \\
Minimum & -12.6690 & -10.6345 & -11.9434 & -13.0649 & -13.0291 & -4.6307 \\
Maximum & 11.9792 & 9.9695 & 17.4267 & 18.3274 & 13.5327 & 8.4238 \\
\hline
\end{tabular}

Source: Author's computation from www.investing.com \& www.quandl.com.

Note: $\mathrm{p}$ values are reported in brackets. Statistically significant at $1 \%, 5 \%$ and $10 \%$.

To check for stationarity in the return series, the unit root tests - the Augmented Dickey-Fuller (ADF) and the Kwaitkowski, Phillips, Schmidt and Shin (KPSS) tests are applied to the NSE-30 price index series and return. While the ADF test is used to test for all returns in the stock market under the null hypothesis of a unit root against the hypothesis of stationarity, the KPSS has a null of stationarity of a series around either mean or a linear trend; and the alternative assumes that a series is non-stationary due to presence of a unit root.

The results in Table 2 suggest that the NSE-30 series contain a unit root in level but stationary with no evidence of unit root in the return at 1,5 and 10 percent level of significance. In other words, the NSE-30 series is integrated of order 1. Therefore, by transforming it in returns, the series will be stationary.

\section{Tab. 2: Unit Root Test}

\begin{tabular}{|c|c|c|c|c|c|}
\hline \multirow[b]{2}{*}{ Variables } & \multicolumn{2}{|c|}{ ADF Test } & \multicolumn{3}{|c|}{$\underline{\text { KPSS Test }}$} \\
\hline & T-Stat & Crit Value & Test Stat & Crit Value & Lag \\
\hline Panel A: Series & & -3.4372 & & $0.7390 *$ & \\
\hline \multirow{2}{*}{ NSE-30 } & -0.7945 & -2.8638 & 14.8915 & $0.4630 * *$ & 04 \\
\hline & & -2.5680 & & $0.3470 * * *$ & \\
\hline Panel B: Return & & $-3.4372 *$ & & 0.7390 & \\
\hline \multirow{2}{*}{ NSE-30 } & -22.4981 & $-2.8638 * *$ & 0.2243 & 0.4630 & 04 \\
\hline & & $-2.5680 * * *$ & & 0.3470 & \\
\hline
\end{tabular}

Source: Author's computation from www.investing.com \& www.quandl.com.

Note: $p$ values are reported in brackets. Statistically significant at $* 1 \%, * * 5 \%$ and $* * * 10 \%$. 


\subsection{Model Specification}

This study uses the Bollerslev (1986) Generalized Autoregressive Conditional Heteroskedasticity (GARCH) and the Nelson (1991) Exponential Generalized Autoregressive Conditional Heteroskedasticity (EGARCH) models. The GARCH models for the mean and variance equations are;

$$
\begin{gathered}
R_{t}=\alpha_{M} M_{t}+\alpha_{T} T_{t}+\alpha_{W} W_{t}+\alpha_{T H} T H_{t}+\alpha_{F} F_{t}+\varepsilon_{t} \\
h_{t}^{2}=V_{c}+\alpha_{i} \varepsilon_{t-1}^{2}+\beta h_{t-1}^{2}+V_{M} M_{t}+V_{T} T_{t}+V_{W} W_{t}+V_{T H} T H_{t}+V_{F} F_{t} \\
\text { Where } \mathrm{V}_{\mathrm{c}} \geq 0, \alpha_{\mathrm{i}} \geq 0, \beta_{\mathrm{j}} \geq 0 \quad \mathrm{i}=1,2,3 \ldots \mathrm{q} \text { and } \mathrm{j}=1,2,3 \ldots \mathrm{p}
\end{gathered}
$$

If the sum parameter $\alpha_{i}+\beta_{j}<1$, then equation (3) will be stationary, but if close to 1 , the volatility parameter will be more persistent. The coefficients $M_{t}, T_{t}, W_{t}$, $\mathrm{TH}_{\mathrm{t}}$, and $\mathrm{F}_{\mathrm{t}}$ are dummy variables for Monday, Tuesday, Wednesday, Thursday and Friday while $\alpha_{\mathrm{M}}, \alpha_{\mathrm{T}}, \alpha_{\mathrm{W}}, \alpha_{\mathrm{TH}}, \alpha_{\mathrm{F}}$ are the estimated coefficient. The dummy variable trap is avoided with the exclusion of the constant in the model (Berument and Kiymaz (2001);

$$
H_{0}: \alpha_{M}=\alpha_{T} \cdots \alpha_{F}=0 \text { Vs } H_{1}: \alpha \neq 0 \quad \text { for } i=1, \cdots 5
$$

A rejection of the null hypothesis implies the presence of daily seasonality. The equation for the EGARCH model is,

$$
\begin{gathered}
\mathrm{R}_{\mathrm{t}}=\alpha_{\mathrm{M}} \mathrm{M}_{\mathrm{t}}+\alpha_{\mathrm{T}} \mathrm{T}_{\mathrm{t}}+\alpha_{\mathrm{W}} \mathrm{W}_{\mathrm{t}}+\alpha_{\mathrm{TH}} \mathrm{TH}_{\mathrm{t}}+\alpha_{\mathrm{F}} \mathrm{F}_{\mathrm{t}}+\varepsilon_{\mathrm{t}} \\
\log \left(h_{t}^{2}\right)=V_{c}+\alpha_{1}\left|\frac{\varepsilon_{t-1}}{\sqrt{h_{t-1}}}\right|+\beta \log \left(h_{t-1}\right)+\gamma \frac{\varepsilon_{t-1}}{h_{t-1}}+V_{M} M_{t}+V_{T} T_{t} \\
+V_{W} W_{t} \cdot+V_{T H} T H_{t}+V_{F} F_{t}
\end{gathered}
$$

The logarithm of the conditional variance ensures that the forecasts of the conditional variance are stationary and guaranteed to be nonnegative. The EGARCH model also allows the investigation of leverage effect. If $\gamma=0$, then a positive $\left(\varepsilon_{\mathrm{t}-1} / \mathrm{h}_{\mathrm{t}-1}>0\right)$ has the same magnitude effect as a negative surprise. However, if $-1<y<0$, a positive surprise increases volatility less than a negative surprise does, but if $\mathrm{Y}<-1$, then a positive surprise decreases volatility while a negative surprise increases volatility (Berument et al, (2007)). The standard error coefficients were estimated by the Broyden, Fletcher, Goldfarb, Shanno (BFGS) iteration optimization.

In order to account for excess kurtosis, this study assumed the three main distributional assumption - the Gaussian, the student-t and the generalized error distribution (GED). Rahman et al (2013) states the Gaussian distribution, symmetric distribution with density function given as, 


$$
f(x)=\frac{1}{\sqrt{2 \pi \sigma^{2}}} e^{-(x-\mu)^{2} / \sigma^{2}}
$$

Where $\mu$ is the mean value, and $\sigma^{2}$ is the variance of the stochastic variable. The standard Gaussian distribution considers the mean value $\mu=0$ and variance $\sigma^{2}=1$. Although the Guassian distribution possess the leptokurtic property, but this property is not enough to explain the leptokurtosis property found in most of the financial data. Another error distributional assumption used in this study is the student-t distribution which takes into account the leptokurtic distribution for the error, with density function given as;

$$
f(x)=\frac{\Gamma[(v+1) / 2]}{\sqrt{v \pi[v / 2]\left(1+x^{2} / 2\right)^{(v+1) / 2}}}
$$

Where $v$ is the degree of freedom $(v>2)$. If $v$ tend to $\infty$, the student-t distribution converges to the Gaussian distribution. The implied kurtosis of the student-t distribution is $k=(6 / v-4)+3$ for all $v>4$. In addition to the Gaussian and the student-t distribution, this study also used the generalized error distribution (GED). The GED is a symmetric distribution and platykurtic with density function;

$$
f(x)=\frac{v e^{\frac{1}{2}\left|\frac{x}{\lambda}\right|}}{\lambda 2^{(v+1) / v} \Gamma \frac{1}{v}}
$$

Where $\Gamma(\cdot)$ is the gamma function and $\lambda=\left[\left(2^{-2 / v} \Gamma\left(\frac{1}{v}\right)\right) / \Gamma\left(\frac{3}{v}\right)\right]^{\frac{1}{2}}$. If the parameter $\mathrm{v}$ has the value 2 it become standardized normal and so the distribution reduces to normal distribution. The implied kurtosis of the GED is, $\Gamma\left(\frac{1}{v}\right) \Gamma\left(\frac{5}{v}\right) / \Gamma\left(\frac{3}{v}\right)^{2}$. Although the GED distribution may be better able to capture peaks, it is far worse for capturing fat tails. 


\section{Empirical results and discussions}

Tables 3 and 4 report the estimate of the specifications in equations (2), (2"), (3) and (4) under the three distributional assumptions. In other to capture more autocorrelation, more lagged values (second lagged) of the NSE-30 prices are included in the variance equation for both the GARCH $(2,1)$ and EGARCH $(2,1)$ models. There is disappearance of day-of-the-week dummies in the mean when the GARCH $(2,1)$ and EGARCH $(2,1)$ models are used under the Gaussian distribution. But with the GARCH $(2,1)$ model, day-of-the-week effects are observed when the day-of-the-week dummies are present in the volatility equation. In the variance equation, the EGARCH $(2,1)$ model also showed absence of dayof-the-week effect.

And just like under the Gaussian distribution, the EGARCH $(2,1)$ model under the student-t distribution also causes disappearance of the day-of-the-week dummies in both the mean and the variance equation. However, the coefficient of the dayof-the-week dummies in the GARCH $(2,1)$ model under the student-t distribution shows anomaly in both returns and volatility. The GARCH $(2,1)$ model under the generalized error distribution (GED) shows presence of the day-of-the-week effect in both in mean and variance equations, there is appearance of day-of-the-week effect in the mean model, and disappearance in the variance equation when the EGARCH $(2,1)$ model is use. In summary, there is inconsistencies and sensitivity in the day-of-the-week effect under different error distributional assumption in the GARCH $(2,1)$ and EAGRCH $(2,1)$ model using the NSE-30.

However, the estimated coefficient for the leverage effect in EGARCH $(2,1)$ model under the three distributional assumptions (Gaussian, student-t and GED) are negative but statistically significant under the GED distribution. If $\gamma$ is negative and statistically significant, it suggests that negative unanticipated changes in the NSE-30 introduces more changes in the conditional variance than positive unanticipated change does. The coefficient of $\beta_{j}$ for both lagged are less than 1 , and this satisfies the non-explosiveness of the conditional variance. Our study shows that the GARCH $(2,1)$ and $\operatorname{EGARCH}(2,1)$ model fit better under the student-t and GED distributions respectively.

Again as shown in both panel B, Table 3 and 4, the asymmetry models seem to cause a disappearance in the variance equations. The highest and lowest volatility days also varies in line with the different error distribution and model applied. In order to assess the robustness of our specification, we provided a set of robustness statistics. These tests are the Ljung-Box autocorrelation test for lag 10, the ARCHLM test for lags 5, 10 and 20, and the Brock, Dechert and Scheinkman (BDS) test. 
Osarumwense, O.: Day-of-the-week effect in the Nigerian Stock Market Returns and Volatility:

Does the Distributional Assumptions Influence Disappearance?

Tab. 3: Daily day-of-the-week in return and volatility with GARCH model

\begin{tabular}{|c|c|c|c|}
\hline & GARCH & CARCH-t & GARCH-GED \\
\hline \multicolumn{4}{|l|}{ Panel A: Returns } \\
\hline \multirow[t]{2}{*}{ Monday } & -0.0156 & $-0.0045 * *$ & -0.0036 \\
\hline & [0.3099] & {$[0.0461]$} & [0.4997] \\
\hline \multirow[t]{2}{*}{ Tuesday } & -0.0336 & $-0.0369 * *$ & $-0.0412 *$ \\
\hline & {$[0.1438]$} & [0.0197] & {$[0.0000]$} \\
\hline \multirow[t]{2}{*}{ Wednesday } & -0.0227 & -0.0161 & -0.0091 \\
\hline & [0.2916] & {$[0.2748]$} & {$[0.3288]$} \\
\hline \multirow[t]{2}{*}{ Thursday } & 0.0012 & 0.0028 & 0.0019 \\
\hline & [0.9537] & [0.3177] & [0.7236] \\
\hline \multirow[t]{2}{*}{ Friday } & 0.0075 & 0.0005 & -0.0050 \\
\hline & {$[0.2581]$} & [0.7529] & {$[0.3002]$} \\
\hline \multicolumn{4}{|c|}{ Panel B: Volatility } \\
\hline \multirow[t]{2}{*}{$V_{C}$} & $0.3228 *$ & $0.3046^{*}$ & $0.1113 *$ \\
\hline & {$[0.0000]$} & {$[0.0000]$} & {$[0.0075]$} \\
\hline \multirow[t]{2}{*}{$\alpha$} & $0.1402 *$ & $0.2193 *$ & $0.1782 *$ \\
\hline & {$[0.0000]$} & {$[0.0000]$} & {$[0.0026]$} \\
\hline \multirow[t]{2}{*}{$\beta\{1\}$} & $0.0731 *$ & $0.1235^{*}$ & 0.0582 \\
\hline & {$[0.0000]$} & {$[0.0000]$} & {$[0.3337]$} \\
\hline \multirow[t]{2}{*}{$\beta\{2\}$} & $0.1757 *$ & $0.1276^{*}$ & $0.5858 *$ \\
\hline & {$[0.0000]$} & {$[0.0000]$} & {$[0.0000]$} \\
\hline \multirow[t]{2}{*}{ Monday } & $0.0353 *$ & $-0.0136^{*}$ & 0.0028 \\
\hline & {$[0.0000]$} & {$[0.0000]$} & {$[0.9380]$} \\
\hline \multirow[t]{2}{*}{ Tuesday } & $-0.0379 *$ & $-0.0170^{*}$ & $-0.0522 *$ \\
\hline & {$[0.0000]$} & {$[0.0000]$} & {$[0.0000]$} \\
\hline \multirow[t]{2}{*}{ Wednesday } & $0.0585^{*}$ & $0.0243 *$ & $0.0295 *$ \\
\hline & {$[0.0000]$} & {$[0.0000]$} & {$[0.0000]$} \\
\hline \multirow[t]{2}{*}{ Thursday } & $0.0528 *$ & $0.0470 *$ & $0.0698 * * *$ \\
\hline & {$[0.0000]$} & {$[0.0000]$} & {$[0.0589]$} \\
\hline \multirow[t]{2}{*}{ Friday } & $-0.0722 *$ & $-0.0247 *$ & -0.0388 \\
\hline & {$[0.0000]$} & {$[0.0000]$} & {$[0.4588]$} \\
\hline \multicolumn{4}{|c|}{ Panel C: Diagnostics test checking } \\
\hline \multirow{3}{*}{$\begin{array}{l}\text { Log-Likelihood } \\
L B Q(10)\end{array}$} & -214.4401 & -215.3077 & -213.8616 \\
\hline & 1.4440 & 0.0965 & 5.8243 \\
\hline & [0.9991] & {$[1.0000]$} & {$[0.7573]$} \\
\hline \multirow[t]{2}{*}{$L B Q^{2}(10)$} & 0.0619 & 0.0651 & 0.6383 \\
\hline & {$[1.0000]$} & {$[1.0000]$} & [0.9996] \\
\hline \multirow[t]{2}{*}{ ARCH-LM (10) } & $2.8120 * * *$ & $3.3500 * *$ & 2.0960 \\
\hline & {$[0.0670]$} & {$[0.0340]$} & {$[0.2610]$} \\
\hline \multirow[t]{2}{*}{ ARCH-LM (15) } & 2.3060 & 2.8930 & $2.1930 * * *$ \\
\hline & {$[0.2466]$} & {$[0.4230]$} & {$[0.0612]$} \\
\hline \multirow[t]{2}{*}{ ARCH-LM (20) } & 1.7700 & 2.2460 & 1.7100 \\
\hline & {$[0.1378]$} & {$[0.2920]$} & {$[0.1552]$} \\
\hline \multirow[t]{2}{*}{ BDS Test } & -0.4790 & -0.1855 & -0.2816 \\
\hline & {$[0.6318]$} & {$[0.8528]$} & {$[0.7782]$} \\
\hline
\end{tabular}

Source: Author's computation from www.investing.com \& www.quandl.com.

Note: $p$ values are reported in brackets. Statistically significant at $* 1 \%$, **5\% and $* * * 10 \%$. 
European Financial and Accounting Journal, 2015, vol.10, no. 4, pp. 33-44.

Tab. 4: Daily day-of-the-week in return and volatility with EGARCH model

\begin{tabular}{|c|c|c|c|}
\hline & EGARCH & EGARCH-t & EGARCH-GED \\
\hline \multicolumn{4}{|l|}{ Panel A: Returns } \\
\hline Monday & $\begin{array}{l}-0.0170 \\
{[0.6828]}\end{array}$ & $\begin{array}{l}-0.0150 \\
{[0.7201]}\end{array}$ & $\begin{array}{l}0.0045 \\
{[0.2710]}\end{array}$ \\
\hline Tuesday & $\begin{array}{l}-0.0472 \\
{[0.1163]}\end{array}$ & $\begin{array}{l}-0.0191 \\
{[0.4712]}\end{array}$ & $\begin{array}{l}-0.0118^{*} \\
{[0.0025]}\end{array}$ \\
\hline Wednesday & $\begin{array}{l}-0.0046 \\
{[0.9316]}\end{array}$ & $\begin{array}{l}-0.0407 \\
{[0.3845]}\end{array}$ & $\begin{array}{l}0.0196^{*} \\
{[0.0000]}\end{array}$ \\
\hline Thursday & $\begin{array}{l}-0.0058 \\
{[0.9186]}\end{array}$ & $\begin{array}{l}0.0294 \\
{[0.5492]}\end{array}$ & $\begin{array}{l}0.0003 * * \\
{[0.0292]}\end{array}$ \\
\hline Friday & $\begin{array}{l}0.0113 \\
{[0.8452]} \\
\end{array}$ & $\begin{array}{l}-0.0085 \\
{[0.8808]} \\
\end{array}$ & $\begin{array}{c}-0.0081^{*} \\
{[0.0000]}\end{array}$ \\
\hline \multicolumn{4}{|l|}{ Panel B: Volatility } \\
\hline $\mathrm{V}_{\mathrm{C}}$ & $\begin{array}{l}-0.3353^{* *} \\
{[0.0262]}\end{array}$ & $\begin{array}{l}-0.3170 * * \\
{[0.0405]}\end{array}$ & $\begin{array}{l}0.9072 * \\
{[0.0000]}\end{array}$ \\
\hline$\alpha$ & $\begin{array}{l}0.2369 * * * \\
{[0.0836]}\end{array}$ & $\begin{array}{l}0.3003 * * * \\
{[0.0822]}\end{array}$ & $\begin{array}{l}0.9237 * \\
{[0.0000]}\end{array}$ \\
\hline$\beta\{1\}$ & $\begin{array}{l}0.3736^{*} \\
{[0.0000]}\end{array}$ & $\begin{array}{l}0.5748^{*} \\
{[0.0091]}\end{array}$ & $\begin{array}{l}-0.1151 \\
{[0.3041]}\end{array}$ \\
\hline$\beta\{2\}$ & $\begin{array}{l}0.4456^{*} \\
{[0.0000]}\end{array}$ & $\begin{array}{l}0.2896 \\
{[0.1542]}\end{array}$ & \\
\hline$\gamma$ & $\begin{array}{l}-0.0724 \\
{[0.2586]}\end{array}$ & $\begin{array}{l}-0.0978 \\
{[0.2361]}\end{array}$ & $\begin{array}{l}-0.3245^{*} \\
{[0.0029]}\end{array}$ \\
\hline Monday & $\begin{array}{l}0.0828 \\
{[0.3670]}\end{array}$ & $\begin{array}{l}-0.0307 \\
{[0.8240]}\end{array}$ & $\begin{array}{l}-0.0313 \\
{[0.5730]}\end{array}$ \\
\hline Tuesday & $\begin{array}{l}-0.0327 \\
{[0.7043]}\end{array}$ & $\begin{array}{l}-0.0512 \\
{[0.6613]}\end{array}$ & $\begin{array}{l}-0.0496 \\
{[0.4281]}\end{array}$ \\
\hline Wednesday & $\begin{array}{l}0.0002 \\
{[0.9987]}\end{array}$ & $\begin{array}{l}0.0540 \\
{[0.8380]}\end{array}$ & $\begin{array}{l}0.0351 \\
{[0.4685]}\end{array}$ \\
\hline Thursday & $\begin{array}{l}0.1946 \\
{[0.2672]}\end{array}$ & $\begin{array}{l}0.2645 \\
{[0.2262]}\end{array}$ & $\begin{array}{l}0.0560 \\
{[0.2595]}\end{array}$ \\
\hline Friday & $\begin{array}{l}-0.1845 \\
{[0.1830]}\end{array}$ & $\begin{array}{l}-0.1871 \\
{[0.3317]}\end{array}$ & $\begin{array}{l}-0.0495 \\
{[0.3381]}\end{array}$ \\
\hline Panel C: Diagnos & est checking & & \\
\hline Log-Likelihood & -214.9065 & -215.4644 & -260.3812 \\
\hline$L B Q(10)$ & $\begin{array}{l}1.7717 \\
{[0.9945]}\end{array}$ & $\begin{array}{l}3.5289 \\
{[0.9396]}\end{array}$ & $\begin{array}{l}0.3289 \\
{[1.0000]}\end{array}$ \\
\hline$L B Q^{2}(10)$ & $\begin{array}{l}22.9640 \\
{[0.1534]}\end{array}$ & $\begin{array}{l}26.6530 \\
{[0.2379]}\end{array}$ & $\begin{array}{l}15.3554 * * * \\
{[0.0525]}\end{array}$ \\
\hline ARCH-LM (10) & $\begin{array}{l}2.0250 \\
{[0.4330]}\end{array}$ & $\begin{array}{l}1.7260 * * * \\
{[0.0778]}\end{array}$ & $\begin{array}{l}2.2920 \\
{[0.1147]}\end{array}$ \\
\hline ARCH-LM (15) & $\begin{array}{l}1.6610 * * * \\
{[0.0628]}\end{array}$ & $\begin{array}{l}1.4020 \\
{[0.1509]}\end{array}$ & $\begin{array}{l}2.1070 \\
{[0.1115]}\end{array}$ \\
\hline ARCH-LM (20) & $\begin{array}{l}1.2670 \\
{[0.2079]}\end{array}$ & $\begin{array}{l}1.1350 \\
{[0.3193]}\end{array}$ & $\begin{array}{l}1.8490 \\
{[0.2331]}\end{array}$ \\
\hline BDS Test & $\begin{array}{l}0.1309 \\
{[0.8958]}\end{array}$ & $\begin{array}{l}0.7629 \\
{[0.4454]}\end{array}$ & $\begin{array}{l}0.1462 \\
{[0.8837]}\end{array}$ \\
\hline
\end{tabular}

Source: Author's computation from www.investing.com \& www.quandl.com.

Note: $p$ values are reported in brackets. Statistically significant at $* 1 \%$, **5\% and $* * * 10 \%$. 
The p-values of these tests shown in panel $\mathrm{C}$ tables 3 and 4 cannot reject the null hypothesis that they are statistically significant at conventional $1 \%, 5 \%$ and $10 \%$. Therefore, our robustness tests result supports and confirms the validity of our models specification.

\section{Conclusion}

This study assesses comprehensively the day-of-the-week in the Nigeria stock exchange (NSE-30) in returns and volatility, under the three main error distributional assumptions for the period of May $31^{\text {st }} 2011$ to May $2^{\text {nd }} 2015$. The GARCH $(2,1)$ and EAGRCH $(2,1)$ models are used to capture the volatility clustering effect as well as the leverage effects. However, the evidence presented in this study reveals that; (1) The day-of-the-week in the Nigeria stock exchange (NSE-30) in returns and volatility is sensitive to the distributional assumptions. Our empirical evidence shows that the day-of-the-week anomalies vary depending on the assumption made on returns and variance. In other words, the idea of dayof-the-week effect in the Nigerian stock market is not real as error distributional assumption influences the appearance or disappearance of calendar effects. Therefore, academic researchers, investors, policy makers etc, investigating the relationship between the Nigerian stock exchange prices and returns or variance should take into consideration the error distributional assumption. (2) The asymmetry does not seem to influence the appearance or disappearance of the seasonal effects. In addition, our results indicate that the asymmetric effects as a result of the leverage effect also depend on the choice of the model used.

\section{Acknowledgment}

My sincere thanks go to the editor and the two anonymous referees for their very helpful comments and suggestions. For any other error(s), the usual disclaimer applies. 


\section{References}

Ajibola, A., Nwakanma P. C., 2014. Detecting Market Anomalies: Do Evidences hold in Nigeria? International Review of Management and Business Research 2, 1128-1138.

Alagidede, P., 2008. Day-of-the-week seasonality in African stock markets. Applied Financial Economics Letters 2, 115-120.

Al-Mutairi, A., 2010. An investigation of the day-of-the-week effect in the Kuwait stock exchange. Research Journal of International Studies 16, 191-197.

Basher, S. A., Sadorsky, P., 2006. Day-of-the-Week Effect in Emerging Stock Markets. Applied Economics Letters 13, 621-628.

Berument, H., Coskun, M. N., Sahin, A., 2007. Day-of-the-Week Effect on the Foreign Exchange Market Volatility: Evidence from Turkey. Research in International Business and Finance 21, 87-97.

Bollerslev, T., 1986. Generalised Autoregressive Conditional Heteroscedasticity. Journal of Econometrics 31, 307-327.

Brooks, C., Persand, G., 2001. Seasonality in Southeast Asian stock markets: Some new evidence on the day-of-the-week effects. Applied Economics Letters 8, 155-158.

Charles, A., 2010. The Day-of-the-Week Effect on the Volatility. The Role of the Asymmetry. European Journal of Operational Research 202, 143-152.

Chipili, J. M., 2012. Day-Of-The-Week Effect In Returns And Volatility Of The Kwacha/Us Dollar Exchange Rate. Authorised for Distribution by DirectorFinancial Markets as working Paper WP/01/2012, Bank of Zambia.

Claessens, S., Dasgupta, S., Glen, J., 1995. The cross-section of stock returns: Evidence from emerging markets. Policy Research Working Paper Series, the World Bank No. 1505.

Cross, F., 1973. The behaviour of stock prices on Fridays and Mondays. Financial Analysts Journal 29, 67-69.

French, K., 1980. Stock returns and the weekend effect. Journal of Financial Economics 8, 55-69.

Gibbons, M., Hess, P., 1981. Day-of-the-week effects and asset returns. Journal of Business 54, 579-596.

Gultekin, M. N., Gultekin, N. B., 1983. Stock market seasonality: International evidence. Journal of Financial Economics 12, 469-481.

Keim, D. B., Stambaugh, F., 1984. A further investigation of weekend effects in stock returns. Journal of Finance 39, 819-840. 
Kiymaz, H., Berument, H., 2003. The Day-of-the-week Effect on Stock Market Volatility and Volume: International Evidence. Review of Financial Economics 12, 363-380.

Nelson, D. B., 1991. Conditional Heteroskedasticity in Asset Returns: A New Approach. Econometrica 59, 347-370.

Oladayo, O., 2015. The January and Monday effect or the lack thereof. Mathematical Theory and Modeling 4.

Olowe, R. A., 2011. Exchange Rate Volatility, Global Financial Crisis and the Day-of-the- Week Effect. KJBM 3.

Osazevbaru, H. O., Oboreh, J., 2014. The "Monday Effect" in Nigerian Stock Market: Evidence and Implication. Journal of Social Sciences and Public Policy 1, 1-8.

Rahman, Md. M., Rahman, Md. A., Hossain, Md. A., 2013. Volatility Modeling for forecasting stock index with fixed parameter distributional assumption. Journal of Applied Finance \& Banking 1, 109-122.

Rozeff, M., Kinney, W., 1976. Capital market seasonality: the case of stock returns. Journal of Financial Economics 3, 379-402.

Saadi, S., Rahman, A., Chourou, L., 2006. Day-of-the-Week in Returns and Conditional Volatility: A Fact or Fiction? Evidence from Spot CAD/USD Foreign Exchange Rates. 6th Global Conference on Business and Economics, October 1517, Gutman Conference Centre, USA.

Umar, B. N., 2013. The Day-of-the-week effect on stock market returns and volatility: Evidence from Nigeria and South Africa. MPRA Paper No. 48076. 